\title{
Gestão das pandemias sob a ótica da bioética principialista
}

\author{
Management of pandemics from the perspective of principlist bioethics
}

\author{
Manejo de pandemias desde la perspectiva de la bioética principialista
}

Caiuze Aguiar Nunes ${ }^{1 *}$, Cattiúscia Batista Bromochenkel ${ }^{2}$, Chrisne Santana Biondo ${ }^{3}$, Gabriela Donha Yarid Angelieri ${ }^{4}$, Taís Donha Yarid Angelieri ${ }^{5}$, Sérgio Donha Yarid ${ }^{6}$

Como citar esse artigo. Nunes, CA; Bromochenkel, $\mathrm{CB}$; Biondo, CS; Angelieri, GDY; Angelieri, TDY; Yarid, SD. Gestão das pandemias sob a ótica da bioética principialista. Revista PróUniverSUS. 2021 Jan./Jun.; 12 (1): 8693.

\section{Resumo}

Introdução: Na última década, foram registradas duas pandemias de grande impacto em saúde pública, a causada pelo vírus Influenza A, em 2009, e pelo SARS-CoV-2, iniciada ao final de 2019. Contudo, suas implicações transpõem os limites sanitários, abarcando questões importantes concernentes aos princípios bioéticos implícitos nestes contextos. O objetivo do estudo foi refletir sobre as medidas adotadas na prevenção e contenção de pandemias, analisando-as sob a ótica da bioética principialista. Materiais e métodos: Estudo descritivo, documental, de natureza qualitativa. Resultados: Observou-se que os países adotaram medidas preventivas no modelo de educação em saúde, limitação de atividades com o distanciamento social e a vigilância dos casos diagnosticados. Considerações finais: Com o estudo, foi possível observar o engajamento de todos os países no enfrentamento das pandemias, respeitando os princípios da bioética, a exceção da justiça e da autonomia, estas restringidas por ações técnicas e governamentais, e por escassez de recursos.

Palavras-chave: Bioética; Controle; Pandemia; Prevenção; Principialismo.

\begin{abstract}
Introduction: In the last decade, two pandemics of great impact on public health have been recorded, those caused by the Influenza A virus in 2009 and SARS-CoV-2, which started in late 2019. However, their implications go beyond sanitary limits, covering important issues concerning the bioethical principles implicit in these contexts. The aim of the study was to reflect on the measures adopted in the prevention and containment of pandemics, analyzing them from the perspective of principlist bioethics. Materials and methods: It were a descriptive, documentary, qualitative study. Results: It was observed that the countries adopted preventive measures in the health education model, limiting activities with social distance and surveillance of diagnosed cases. Final considerations: With the study, it was possible to observe the engagement of all countries in facing pandemics, respecting the principles of bioethics, with the exception of justice and autonomy, which are restricted by technical and governmental actions, and by scarcity of resources
\end{abstract}

Keywords: Bioethics; Controll; Pandemics; Prevention; Principlism.

\begin{abstract}
Resumen
Introducción: En la última década, se han registrado dos pandemias de gran impacto en la salud pública, la causada por el virus de la Influenza A en 2009 y el SARS-CoV-2, que comenzó a fines de 2019. Sin embargo, sus Las implicaciones van más allá de los límites sanitarios y abarcan cuestiones importantes relacionadas con los principios bioéticos implícitos en estos contextos. El objetivo del estudio fue reflexionar sobre las medidas adoptadas en la prevención y contención de pandemias, analizándolos desde la perspectiva de la bioética principialista. Materiales y métodos: estudio descriptivo, documental y cualitativo. Resultados: Se observó que los países adoptaron medidas preventivas en el modelo de educación en salud, limitando las actividades con distancia social y vigilancia de los casos diagnosticados. Consideraciones finales: Con el estudio, fue posible observar la participación de todos los países en enfrentar pandemias, respetando los principios de la bioética, con la excepción de la justicia y la autonomía, que están restringidas por acciones técnicas y gubernamentales, y por la escasez de recursos.
\end{abstract}

Palabras clave: Bioética; Control; Pandemias; Prevención; Principialismo.

Afiliação dos autores: ${ }^{1}$ Mestranda em Ciências da Saúde pelo Programa de Pós-Graduação em Enfermagem e Saúde - UESB Jequié, Bahia, Brasil. ORCID: https://orcid.org/00000002-5731-2641.

${ }^{2}$ Mestranda em Ciências da Saúde pelo Programa de Pós-Graduação em Enfermagem e Saúde pela UESB, Bahia, Brasil. ORCID: https://orcid.org/0000-0002-2514-0734.

${ }^{3}$ Doutoranda em Ciências da Saúde pelo Programa de Pós-Graduação em Enfermagem e Saúde da UESB. Professora assistente da UFBA, Jequié, Bahia, Brasil. ORCID: https:// orcid.org/0000-0002-0583-5491.

${ }^{4}$ Estudante de Medicina na Universidade Cidade de São Paulo, Pinheiros, São Paulo, Brasil. ORCID: https://orcid.org/0000-0001-7761-8528.

${ }^{5}$ Estudante de Medicina na Universidade Cidade de São Paulo, Pinheiros, São Paulo, Brasil. ORCID: https://orcid.org/0000-0002-2915-2265.

${ }^{6}$ Doutor em Odontologia Preventiva e Social pela UNESP. Professor Titular da Universidade Estadual do Sudoeste da Bahia - UESB - Departamento de Saúde, Jequié, Bahia, Brasil. ORCID: https://orcid.org/0000-0002-6447-0453

Artigo Premiado no I Congresso Interinstitucional de Espiritualidade em Saúde

*Email de correspondencia: yarid@uesb.edu.br

Recebido em: 21/01/21. Aceito em: 29/04/21. 


\section{Introdução}

Desde os tempos históricos, momentos de epidemia e pandemia trazem pânico para a população e situações conflitantes para os gestores, que necessitam adotar medidas para minimizar as consequências da enfermidade, tanto pela sobrecarga nos sistemas de saúde quanto a crise econômica que surge em decorrência do adoecimento da população. Nos últimos 10 anos, ocorreram duas pandemias, a ocasionada pelo vírus Influenza A (H1N1) em 2009, e pelo SARSCoV-2 (Covid-19), que teve início em novembro 2019, ambas com grande potencial de transmissibilidade e disseminando-se através do sistema respiratório das pessoas.

Nestes contextos, a Organização Mundial de Saúde (OMS) norteia suas recomendações por meio de documentos oficiais como a Resolução Sanitária Internacional (RSI), firmada em 2005, a fim de garantir deliberação adequada aos riscos iminentes à saúde pública, evitando e/ou restringindo a disseminação de doenças em nível internacional ${ }^{1}$. Entre as estratégias adotadas, têm-se, por exemplo, medidas instituídas como a quarentena, isolamento e o distanciamento social, que interferem diretamente em aspectos dos direitos humanos e das liberdades individuais, com repercussão no âmbito coletivo, desde os círculos sociais primários, a exemplo das configurações familiares, aos de caráter mais abrangente, no tocante às populações de cidades, estados e países, e portanto tendo alcance para além de uma abordagem pautada na vigilância sanitária, tornando-se um debate bioético.

Diante disso, a bioética representa importante instrumento para adoção de soluções razoáveis e prudentes, assim, o principialismo relaciona-se à tomada de decisão, respeitando os princípios da beneficência, autonomia, não maleficência e justiça, esta última inclui a distribuição de recursos respeitando a equidade, com atenção aos mais vulneráveis ${ }^{2}$, além dos grupos de riscos específicos de acordo com a enfermidade.

Originalmente, a bioética não estava voltada para as questões sanitárias, ou discutia aspectos acerca da saúde pública, porém elas se relacionam quando se enfatiza a importância de serem considerados os conceitos de justiça e de equidade, fundamentos éticos para uma adequada alocação dos recursos e para garantir acesso aos serviços de saúde. Outro ponto importante é relacioná-la à bioética global, entendendo esta como decorrente da expansão das fronteiras sanitárias e refletindo a preocupação com a dimensão internacional quando se trata da diversidade de problemas de saúde global $^{3}$, principalmente quando relacionados às pandemias.

Nesse sentido, o estudo dessa temática é de suma relevância no campo da saúde, uma vez que se espera que haja reflexão sobre a necessidade de considerar a bioética na resolução de dilemas e problemas bioéticos, que surgem em situações conflitantes, como ocorrem nas pandemias. Além disso, necessita fomentar discussão da temática no âmbito acadêmico, a fim de que os estudantes estejam sensibilizados para lidarem com situações semelhantes na prática profissional.

Diante do exposto, o presente estudo tem por objetivo refletir sobre as medidas adotadas na prevenção e contenção de pandemias, analisando-as sob a ótica da bioética principialista.

\section{Metodologia}

Trata-se de um estudo descritivo, documental, de natureza qualitativa, realizado a partir de dados coletados nos sites oficiais dos países, escolhidos dois países da América do Norte, um da América do Sul, um do continente europeu e um asiático, respeitando os critérios de inclusão, de países que vivenciaram maiores números de casos e óbitos pela doença e aqueles que disponibilizavam o material em português, espanhol ou inglês. Foram excluídos os materiais que não apresentavam os planos de ações no manejo da pandemia.

Sendo assim, os países que tiveram seus planos analisados foram a China, epicentro da pandemia por Covid-19, Itália e Estados Unidos da América, por terem elevado números de casos na pandemia da Covid19, México, local onde iniciaram-se os casos do H1N1, e Brasil, por ser um dos países com maior número de casos e óbitos.

A coleta de dados respeitou os planos disponibilizados de 2009 até setembro de 2020. A partir da leitura e análise do material selecionado, constituído de artigos, diretrizes e protocolos, foram elencadas as principais medidas instituídas, fazendo-se uma reflexão sob a ótica da bioética principialista, o que serviu para embasar as discussões narrativas no desenvolvimento deste estudo. Por se tratar de estudo utilizando bases de dados públicas, não foi necessária a aprovação pelo Comitê de Ética em Pesquisa (CEP).

\section{Resultados e Discussão}

A Influenza A afeta de forma aguda o sistema respiratório e apresenta morbimortalidade agravada nos pacientes pertencentes ao grupo de risco, em que pode se manifestar com acometimento pulmonar de forma grave 4 . Já o SARS - Cov - 2 induz, em casos graves, uma tempestade de citocinas, levando à ativação da cascata de coagulação, causando fenômenos trombóticos e podendo atingir vários órgãos, sendo o pulmão um dos mais afetados ${ }^{5}$. 
Nesse sentido, os casos são mais agravados nos pacientes pertencentes aos grupos de riscos, perfis que serão descritos a seguir. Durante a pandemia da Influenza A, estabeleceu-se risco aumentado em crianças de 0 a 14 anos e jovens adultos até 29 anos, pessoas com doenças pulmonares crônicas ou asma moderada a grave; pessoas imunocomprometidas, incluindo pacientes em tratamento para câncer; e pessoas com diabetes mal controlada, pois apresentavam o risco de complicações. Já os grupos de risco para o desenvolvimento de agravos da Covid-19, segundo a $\mathrm{OMS}^{6}$, são as pessoas com 60 anos ou mais; pessoas com doenças pulmonares crônicas ou asma moderada a grave; com problemas cardíacos; imunocomprometidas, incluindo pacientes em tratamento para câncer; aqueles com Índice de Massa Corpórea (IMC) maior ou igual a 40; e pessoas com diabetes, insuficiência renal ou problemas hepáticos, especialmente aqueles com a doença mal controlada.

As gestantes devem ser monitoradas devido ao risco elevado de complicações, mas não há informação clara sobre a relação com Covid-19, no entanto, pode não estar associado à ocorrência de partos prematuros ou baixo peso ao nascer, sugere-se a possibilidade de transmissão vertical do SARS-CoV-2, portanto, as evidências até o momento são incertas. Devido a essa possibilidade, as gestantes e puérperas entraram no grupo de risco ${ }^{7}$.

Nesse contexto, a apresentação do panorama de casos e óbitos das duas pandemias são apresentados na Tabela 1. Ao final da pandemia por H1N1, os boletins epidemiológicos apresentaram maior número de casos registrados nos EUA. Dos países avaliados, o México, local onde foi evidenciado o primeiro caso de H1N1, foi o país com menor número. Quando se trata da pandemia atual, a Covid-19, obteve-se a maioria dos casos também nos EUA, que ultrapassou os números da China, epicentro da doença, o menor números de casos foi no México. Com relação aos óbitos, o Brasil e os EUA registraram maior número de óbitos na pandemia por H1N1; já na da Covid-19, a Itália. Os números reais da pandemia são incertos, uma vez que apenas casos graves foram testados para o vírus Influenza A, e quanto à COVID-19, só os casos que necessitavam de atendimento médico, seja em hospitais ou atenção primária, eram testados, não sendo feitos testes em massa para diagnosticar os assintomáticos.

Após a H1N1 ser anunciada como pandemia pela OMS, no final de abril de 2009 a Itália criou um Comitê Nacional de Gerenciamento de Crises, coordenado pelo Ministério da Saúde. O Comitê ficou no comando de coordenar as estratégias de preparação, resposta e comunicação durante a pandemia e iniciou-se o sistema de vigilância para detectar indivíduos que apresentassem doença semelhante a gripe-influenza-like illness (ILI), com histórico recente de viagens para áreas afetadas (México e EUA), bem como de seus contatos próximos.
Tabela 1. Panorama dos casos, óbitos e taxa de letalidade da Influenza A e Covid-19 nos países selecionados, $2020^{8-13}$.

\begin{tabular}{|c|c|c|}
\hline Variáveis & H1N1*1 & COVID-19*2 \\
\hline \multicolumn{3}{|c|}{ Casos } \\
\hline Brasil & 53.797 & 4.455 .386 \\
\hline Itália & 14.000 & 294.932 \\
\hline China & 120.940 & 90.814 \\
\hline EUA & 60,8 milhões & 6.613 .737 \\
\hline México & 44.070 & 688.954 \\
\hline \multicolumn{3}{|c|}{ Óbitos } \\
\hline Brasil & 2176 & 134.935 \\
\hline Itália & 260 & 35.668 \\
\hline China & 800 & 4.744 \\
\hline EUA & 12.469 & 196.465 \\
\hline México & 398 & 72.803 \\
\hline \multicolumn{3}{|c|}{ Taxa de letalidade \% } \\
\hline Brasil & 4,04 & 3,02 \\
\hline Itália & 1,75 & 12,09 \\
\hline China & 0,66 & 5,22 \\
\hline EUA & 0,2 & 2,97 \\
\hline México & 0,9 & 10,56 \\
\hline
\end{tabular}

Dados coletados são do período de março de 2009 a 10 de agosto de 2010

"2 Dados coletados de dezembro de 2019 até 19 de setembro de 2020 , podendo ter maiores números de casos

Fonte: dados do estudo, 2020.

Além disso, foram adotadas algumas medidas de contenção, que incluíram o isolamento precoce de casos e o fechamento preventivo de escolas com mais de 5 casos de ILI, com pelo menos 2 confirmados, além de profilaxia antiviral para contatos próximos de casos e quarentena por 7-10 dias ${ }^{14}$.

Para informar o público e minimizar informações conflitantes de diferentes fontes a respeito da pandemia, a comunicação foi padronizada em nível nacional e foram publicados boletins diários no site do Ministério da Saúde. Outras medidas adotadas foram o uso de drogas antivirais apenas para casos severos da gripe e para pacientes sintomáticos com condições médicas subjacentes, e campanha de educação em saúde para a população geral, recomendando a adoção de medidas não farmacêuticas, como permanecer em casa se doente e cobrir nariz e boca com lenços ou cotovelos ao tossir ou espirrar. ${ }^{14}$.

A preocupação em manter informações fidedignas à população pode ser associada aos valores e 
ao compromisso profissional presente como guia para a reflexão em bioética, associados à veracidade, o ato de ser dizer a verdade, independentemente da situação; e à fidelidade quando se cria a confiança entre o profissional e o paciente. ${ }^{15}$

México, Brasil, Estados Unidos e China publicaram ações para evitar a transmissão acelerada da Covid-19, abrangendo espaços públicos fechados, lugares de trabalho, centros de lazer, serviços comunitários e serviço de transporte público. Todos os países tomaram medidas com o objetivo de proteção à saúde e à vida, baseando-se em evidências científicas de que tais medidas são eficazes na redução dos agravos. Ao considerarmos tais aspectos, compreendemos que tais princípios referem-se aos princípios de beneficência e não-maleficência da bioética principialista, por utilizarem-se de conhecimento técnico para proteger e garantir a saúde, ao passo que visam evitar agravos em saúde ${ }^{16-19}$

Após o início dos casos, o Ministério da Saúde brasileiro realizou recomendações que as autoridades e a população em geral deveriam adotar diante da disseminação da Covid-19 no país. Dentre tais medidas, incluem-se o reforço da prevenção individual com a etiqueta respiratória; o isolamento domiciliar ou hospitalar de pessoas com sintomas da doença por até 14 dias, além da recomendação para que pacientes com casos leves procurem os postos de saúde; a importância da prática da higiene frequente; a desinfecção de objetos e superfícies tocados com frequência; serviços públicos e privados deveriam disponibilizar locais para que os trabalhadores lavassem as mãos com frequência, álcool em gel $70 \%$ e toalhas de papel descartáveis. Outra orientação foi relativa ao uso de máscaras e outros Equipamentos de Proteção Individual (EPI) por parte de profissionais de saúde; as máscaras faciais descartáveis devem ser utilizadas por cuidadores de idosos, mães que estão amamentando e pessoas diagnosticadas com o coronavírus ${ }^{16}$. Tais medidas foram adotadas por todos os países analisados.

Nesse cenário, para avaliar as medidas adotadas, definem-se os princípios da bioética principialista, entre os quais o da autonomia, que se apresenta com maior significância, pressupondo que, para a prática moral, é essencial a existência da pessoa autônoma. O princípio da beneficência é o que estabelece a obrigação moral de agir para o benefício do outro. No princípio da não maleficência, o profissional de saúde tem a obrigação de não causar mal e/ou danos a seu paciente, ao passo que o princípio da justiça defende o direito de todas as pessoas, tanto no que se refere à sua condição de seres humanos, que merecem respeito, quanto no que diz respeito à igualdade nos cuidados e à luta pela distribuição dos limitados recursos para a saúde e do máximo de benefícios para a comunidade ${ }^{20}$. A beneficência quer dizer fazer o bem para o paciente, enquanto que o princípio da justiça faz referência à igualdade de tratamento, proporcionando a cada indivíduo o que lhe é devido, conforme suas necessidades ${ }^{21}$.

Nesse contexto, ao observar as medidas de proteção em saúde adotadas pelos países analisados, nota-se que estes iniciaram tais ações respeitando o princípio da autonomia, pautado pela bioética, que respeita a escolha do sujeito em relação à tomada de decisões referentes à sua saúde, ao não abordarem o não cumprimento de tais medidas como passíveis de punição. Neste sentido, os alertas e as orientações foram realizados com periodicidade alta, no intuito de minimizar a proliferação do vírus, e a ênfase dada pelas campanhas informativas sobre a doença, em primeiro momento, visaram não somente delimitar de forma mais precisa e reduzir à menor área territorial possível os casos registrados, mas também dissipar ou impedir que eventualmente se instaurasse pânico diante de uma infecção ainda com aspecto desconhecida.

Tal aspecto pode ser associado ao princípio de beneficência, ao considerarmos que tais medidas visam reduzir agravos em saúde e proteger a população do aumento de casos, bem como garantir a curva de crescimento da doença com ascensão lenta, ao passo que, desta forma, garante-se também acesso aos serviços de tecnologia dura à população infectada e com sintomas mais graves. Logo, entende-se o distanciamento social como medida eficaz na redução da disseminação da Covid-19, considerando a população como capaz de exercer a autonomia.

No entanto, houve a limitação da autonomia em prevalência da não-maleficência e beneficência, já que essas ações de contenção eram necessárias no momento. Assim, conceitua-se a autonomia no trato das pessoas de forma a capacitá-la a agir autonomamente, sendo que o desrespeito a atitudes e ações que ignoram a autonomia, nega uma igualdade mínima entre as pessoas, ao passo que a não-maleficência é associada a não causar danos e vem da máxima primum non nocere (acima de tudo não causar o dano), de modo que a beneficência é muito mais do que não causar mal, e sim, acima de tudo fazer o bem ${ }^{15}$. Com isso, observa-se que as ações governamentais priorizaram o bem do maior número de pessoas ao instituírem medidas necessárias para impedir a transmissão entre a população.

A respeito das instituições e serviços que muitas pessoas acessavam ao mesmo tempo, estas foram orientadas quanto a normativas de funcionamento e decretos foram veiculados e autorizados para determinarem o fechamento desses ambientes e de ambientes públicos onde pudessem ocorrer aglomerações. Nota-se o cumprimento ao princípio da não-maleficência, ao passo que tais medidas previnem a proliferação da Covid-19 e minimizam os impactos em saúde da população, ao utilizarem do conhecimento científico para tal fim. 
A OMS, através de suas recomendações, instruí aos países e localidades acometidas por doenças infectocontagiosas do trato respiratório, como a Covid19, a fim de prevenir ou conter a sua disseminação em escalas ainda maiores, contudo, cabe a cada Estado avaliar a real situação de saúde pública em seus territórios, considerando as demandas de seus sistemas de assistência em saúde e as implicações sociais de cada medida. Diante da indisponibilidade de vacina e dos conhecimentos limitados acerca do comportamento evolutivo do vírus, e considerando a sua alta capacidade de transmissão comunitária, as autoridades mundiais em saúde têm recomendado e adotado, incluindo pelo Brasil, o isolamento, a quarentena e o distanciamento social $^{1}$.

Ao falar das duas primeiras estratégias isolamento e quarentena- ao recomendá-las e reafirmálas por portarias e decretos locais, as autoridades executivas e de saúde se respaldam no acompanhamento do histórico recente, suspeita e do diagnóstico comprovado caso a caso, critérios amparados pela Resolução Sanitária Internacional (RSI) de $2005^{1}$ e que são corroborados pelos órgãos de pesquisa e serviços de saúde nacionais. No entanto, o distanciamento social se associa muito mais a uma questão de sensibilização e responsabilização por si e por outrem, com repercussão direta no âmbito do convívio em comunidade.

Haja vista essa peculiaridade, os governos e as populações podem protagonizar divergências que extrapolam as dificuldades já impostas a ambos por emergências sanitárias como esta, uma vez que cabe ao poder público conduzir e executar mecanismos de caráter preventivo e de controle em saúde na esfera coletiva, restringindo as atividades de cada pessoa dessa população, sem, para tanto, ferir as liberdades e direitos individuais ${ }^{22}$.

A tomar pelo exemplo a realidade enfrentada no Brasil, no curso da pandemia da Covid-19, o impacto dos esforços em sensibilizar a população quanto à manutenção do distanciamento e de outras condutas pertinentes à intitulidade pelas mídias, nova normalidade, gradativamente, foi sendo enfraquecido, a exemplo do número cada vez mais elevado de registros e relatos de aglomerações informais após os primeiros meses de restrições, e o não uso de máscaras e agentes saneantes para higiene das mãos. Tudo isso converge para que as instâncias governamentais e institucionais adotem métodos para alcançar a população em suas esferas sociais, e assim evitar ao máximo o uso de protocolos de caráter mais imperativo e conflitante.

Por isso, tem-se implementado o incentivo maciço ao ato voluntário de distanciamento social, com o objetivo de prevenir o contágio e preservar grupos vulneráveis e com risco iminente de complicações e alta letalidade, o que sustenta o princípio bioético da autonomia, pois, assim, através do acesso a informações fidedignas e claras sobre o cenário em que ela e os demais membros da sociedade vivenciam, cada pessoa pode perceber a pertinência e os benefícios comuns da estratégia, e colaborar para a diminuição dos índices de propagação da doença. Nesse ponto, adentra-se em um campo de discussões importantes a respeito dos vieses bioéticos intrínsecos às medidas que podem ou, de fato, influenciam profundamente as escolhas, ações e rotinas individuais e coletivas em tempos de crises sanitárias.

Outra medida instituída no Brasil foi a vacinação contra a Influenza, através da Campanha Nacional de Vacinação, priorizando idosos e profissionais de saúde no primeiro momento. Tal medida visou a prevenção para os vírus H1N1, H3N2 e Influenza B, apesar de não proteger contra a Covid-19. Neste sentido, entende-se que a medida ajuda a reduzir a demanda de pacientes com sintomas respiratórios, acelerando o diagnóstico para o coronavírus, além de manter o controle da circulação do vírus Influenza no país ${ }^{9}$. Ao analisar essa decisão, notam-se medidas especiais de proteção às populações de risco para a Covid-19, que são os idosos, considerando, ainda, os profissionais de saúde como pertencentes a este grupo de risco, por estarem em contato direto com as pessoas contaminadas no exercício profissional. Ao se observarem tais medidas e a sua intencionalidade, pode-se associá-las ao princípio bioético da justiça, visto que priorizam a população mais vulnerável.

Nessa perspectiva, a justiça distributiva, presente na bioética, estabelece como condição justa e equitativa dos benefícios pretendidos, ou seja, tratar a população conforme o que é moralmente correto e adequado, mediante a implementação de políticas públicas, visando a distribuição justa, equitativa e apropriada na sociedade, sendo remetido a um dos princípios do Sistema Único de Saúde - SUS, o da equidade, visto que implica em reduzir as desigualdades evitáveis, sejam as socioeconômicas, ou as em saúde, nesse contexto relacionadas ao tratamento equitativo à população pertencente ao grupo de risco 23 .

Outras medidas foram desenvolvidas ao longo do crescimento de casos no país, dentre as quais a atualização online dos dados da pandemia, a criação de canais online para o atendimento da população, a redução de deslocamentos para o trabalho, o adiamento de viagens não essenciais e a recomendação para que instituições de ensino incluíssem, no seu planejamento, a antecipação de férias ou a utilização de ensino à distância, procurando reduzir prejuízos no calendário escolar e proteger a população da rápida disseminação da doença ${ }^{16}$.

Tais medidas foram adotadas no sentido de reduzir a disseminação do vírus, para que os serviços de saúde consigam atender a população infectada. Caso a curva de crescimento não seja minimizada, os serviços de saúde não conseguiriam atender a população, o que 
impactaria no maior número de óbitos em decorrência de complicações causadas pela doença.

Quanto às medidas de recuperação da saúde, existem pesquisas em andamento para o tratamento ou prevenção da Covid-19, seja através de vacinas ou medicamentos. Assim, cientistas no Brasil, da Faculdade de Medicina da Universidade de São Paulo (USP) e do Laboratório de Imunologia do Instituto do Coração (Incor), e no mundo, em países como Alemanha, Austrália, Estados Unidos e China, já se encontram envolvidos em pesquisa para desenvolvimento de vacina para o vírus (Sars-Cov-2), porém, o processo necessita cumprir os parâmetros bioéticos das pesquisas, e para que sejam respeitadas, as pesquisas requerem tempo, o que implica na prevenção da disseminação futura do vírus.

Referente aos aspectos éticos e às normativas que devem ser utilizadas nas pesquisas com seres humanos, encontra-se a Resolução 466 de 2012, que aborda referenciais da bioética, tais como autonomia, não maleficência, beneficência, justiça e equidade, e visa a assegurar os direitos e deveres que dizem respeito aos participantes da pesquisa, à comunidade científica e ao Estado $^{24}$. Nesta perspectiva, os pesquisadores envolvidos nas pesquisas de desenvolvimento das vacinas contra a Covid-19 devem seguir tal normativa, o que justifica a tomada de outras medidas de prevenção, visto que a supracitada percorrerá um caminho ainda longo.

É possível compreender que, ao respeitar os princípios bioéticos na produção de insumos e medicações no âmbito de prevenção em saúde, as vacinas, e no âmbito da recuperação da saúde, referente à testagem de medicamentos, os países respeitam o princípio da não-maleficência, visto que a disseminação de informações e insumos de saúde sem testagem prévia poderiam gerar impactos ainda maiores do que o próprio aumento de casos do vírus.

Diante da indisponibilidade de vacina e dos conhecimentos limitados acerca do comportamento evolutivo do vírus, e considerando a sua alta capacidade de transmissão comunitária, as autoridades mundiais em saúde têm recomendado o distanciamento social, para se evitar a propagação ainda mais rápida da doença. Nesse ponto, adentra-se em um campo de discussões importantes a respeito dos vieses bioéticos intrínsecos às medidas que podem ou, de fato, influenciam profundamente as escolhas, ações e rotinas individuais e coletivas em tempos de crises sanitárias.

Outro ponto observado é a necessidade dos EPI's para a proteção dos profissionais de saúde e dos pacientes sintomáticos respiratórios. Recentemente, o Ministério da Saúde do Brasil recomendou o uso de máscaras de tecido amplamente para a população, pois existem evidências de mitigar a transmissão, principalmente pelos assintomáticos. Nesse sentido, observa-se uma escassez de equipamentos em todo o mundo, o que pode levar à violação do princípio da não-maleficência, aumentando a transmissão e a contaminação entre os profissionais de saúde, o que compromete todo o processo de atenção à saúde em todas as linhas de assistência, e a valorização da vida humana, pilar essencial da bioética.

\section{Considerações finais}

Nesse estudo, foi possível observar que todos os países se engajam no enfrentamento das pandemias, muitas vezes associando conhecimentos em busca de tratamento ou vacina e respeitam os princípios da bioética. No entanto, o princípio da justiça nem sempre é respeitado, pois faltam recursos para toda a população, a exemplo dos aparelhos de ventilação mecânica, já que muitos países não possuem quantitativos suficientes para a demanda.

Com relação aos princípios de beneficência e nãomaleficência, notou-se que todos os países analisados adotaram como medida prioritária o distanciamento social, bem como outras estratégias que garantem a disseminação mais lenta da doença, pautados em estudos científicos para ambas as pandemias, respeitando, assim, esses princípios. Nota-se, ainda, que a experiência no enfrentamento com a pandemia da H1N1 foi de grande relevância para o da Covid-19 quanto aos métodos preventivos.

Nos países investigados, observou-se que o princípio da autonomia também foi limitado por parte dos governantes e profissionais da saúde, visto que as medidas de proteção em saúde são sugeridas e ofertadas no modelo de educação em saúde na maioria dos países, porém, há a utilização de medidas punitivas em alguns países, para os casos de descumprimento dessas medidas. Vale salientar que este estudo possui a limitação temporal, pois foi feito durante o curso da pandemia da Covid-19, e algumas medidas podem ter sido instituídas depois e não foram analisadas, no entanto, possui relevância, pois avaliou as condutas de vários países, possuindo, assim, maior abrangência territorial.

Diante do que foi obtido através deste estudo, fica evidente que são em contextos como estes, de incertezas diversas e com implicações sociopolíticas e em saúde tão duras, que se fazem urgentes novas reflexões quanto ao conhecimento e, por consequência, quanto aos meios pelos quais se faz ou deve se tornar possível a aplicação e manutenção dos alicerces bioéticos fundamentais para o bem-estar das pessoas.

\section{Referências}

1. World Health Organization (WHO). International Health Regulations [Internet]. 2005 [acesso 28 mar 2020]. Disponível: https://apps.who.int/iris/ bitstream/handle/10665/246107/9789241580496-eng.pdf;jsessionid=36E88 0D67E3A4818FFBD30CF44BC6C02? sequence $=1$. 
2. Urbina-Medina H, Brizuela DN, Mizhary JL, Carrizo JI, Betancourt A. Comunicación efectiva y ética en casos de epidemias y pandemias. Archivos Venezolanos de Puericulturay Pediatría [Internet]. 2016 [acesso 28 mar 2020];79(4): 113-117. Disponível: http://ve.scielo.org/scielo. php?script=sci_arttext\&pid=S0004-06492016000400002\&lng=es.

3. Monteiro PJC. Bioética e saúde pública: justiça e equidade no acesso aos cuidados de saúde. [Tese] [Internet]. Brasília: Universidade de Brasília (UNB); 2019 [acesso 28 mar 2020]. Disponível: https://repositorio.unb.br/ bitstream/10482/36152/1/2019_Pl\%C3\%AdnioJos\%C3\%A9CavalcanteMo nteiro.pdf.

4. Rossetto EV, Luna EJDA. Relacionamento entre bases de dados para vigilância da pandemia de influenza A (H1N1) pdm09, Brasil, 2009-2010. Cadernos de Saúde Pública. [Internet]. 2016. 32, e00014115. [acesso 26 ago 2020]. Disponível: https://www.scielosp.org/article/csp/2016.v32n7/ e00014115/.

5. Dolhnikoff M, Duarte $\square$ Neto A N, de Almeida Monteiro RA, Ferraz da Silva LF, Pierre de Oliveira E, Nascimento Saldiva PH, Marcia Negri E. Pathological evidence of pulmonary thrombotic phenomena in severe COVID $\square$ 19. Journal of Thrombosis and Haemostasis.[Internet]. 2020. [acesso 26 ago 2020]. Disponível: https://doi.org/10.1111/jth.14844.

6. World Health Organization (WHO). Coronavírus Overview [Internet]. 2020 [acesso 28 mar 2020]. Disponível: https://www.who.int/health-topics/ coronavirus\#tab $=$ tab 1 .

7. Melo, G. C. D., \& Araújo, K. C. G. M. D. COVID-19 em gestantes, parto prematuro, peso ao nascer e transmissão vertical: uma revisão sistemática e metanálise. 2020. Cadernos de Saúde Pública, 36.

8. Brasil. Ministério da Saúde. Coronavírus Brasil [Internet]. 2020 [acesso 28 mar 2020]. Disponível: https://covid.saude.gov.br.

9. Casos nos EUA Covid-19. CDC [Internet]. 2020 [a

cesso 28 mar 2020]. Disponível: https://www.cdc.gov/coronavirus/2019ncov/cases-updates/cases-in-us.html.

10. Covid-19 Italia: Monitoraggio della situazione. Dipartimento della Protezione Civile[Internet]. 2020 [acesso 28 mar 2020]. Disponível: http://opendatadpc.maps.arcgis.com/apps/opsdashboard/index.html\#/ b0c68bce2cce478eaac82fe38d4138b1.

11. Nuevo Coronavirus en el mundo Covid-19: Comunicado Técnico Diario [Internet]. Gobierno de México; 2020 [acesso 28 mar 2020]. Disponível: https://www.gob.mx/salud/prensa/nuevo-coronavirus-en-elmundo-covid-19-comunicado-tecnico-diario-239154.

12. Enfu Chen, Simon Cauchemez, Christl A. Donnelly, Lei Zhou, Luzhao Feng, Nijuan Xiang et al. Transmission Dynamics, Border Entry Screening, and School Holidays during the 2009 Influenza A (H1N1) Pandemic, China. Emerging Infectious Diseases [Internet]. 2012 [acesso 28 mar 2020]; 18(5):758-66. Disponível: https://wwwnc.cdc.gov/eid/article/18/5/11-0356 article.

13. 2009 H1N1 Pandemic. CDC [Internet]. 2019 [acesso 28 mar 2020]. Disponível: $\quad$ https://www.cdc.gov/flu/pandemic-resources/2009-h1n1pandemic.html.

14. Rizzo C, Rota MC, Bella A, Giannitelli S, Santis S, Nacca G. Response to the 2009 influenza A(H1N1) pandemic in Italy. Euro Surveill [internet]. 2010 [acesso 28 mar 2020]. Disponível: http://www.eurosurveillance.org/ ViewArticle.aspx?ArticleId=19744.

15. Beauchamp T Childress J. Principles of Biomedical Ethics. 5. ed. Oxford: Oxford University Press, 2001.

16. Brasil. Ministério da Saúde. Saúde anuncia orientações para evitar a disseminação do coronavírus. [acesso 28 mar 2020]. Disponível: https://www. saude.gov.br/noticias/agencia-saude/46540-saude-anuncia-orientacoespara-evitar-a-disseminacao-do-coronavirus.

17. Lineamiento General para la mitigación y prevención de Covid19 en espacios públicos cerrados Gobierno de México [Internet]. 2020 [acesso 28 mar 2020]. Disponível:https://coronavirus.gob.mx/wp-content/ uploads/2020/03/Lineamiento_Espacio_Cerrado_27032020.pdf.

18. Guidance on Preparing Workplaces for Covid-19. Occupational Safety and Health Act [Internet]. 2020 [acesso 28 mar 2020]. Disponível: https://www.osha.gov/Publications/OSHA3990.pdf.
19. Wilder-Smith A, Freedman DO. Isolation, quarantine, social distancing and community containment: pivotal role for old-style public health measures in the novel coronavirus (2019-nCoV) outbreak. J Travel Med [Internet]. 2020 [acesso 28 mar 2020]; 27(2). DOI: 10.1093/jtm/ taaa020.

20. Paiva FCL, Júnior JAJ, Damásio AC. Ética em cuidados paliativos: concepções sobre o fim da vida. Rev. Bioét. [internet] 2014 Abr [acesso 28 mar 2020]. 22(3):550-560. DOI:10.1590/1983-80422014223038.

21. Felix ZC, Batista PSS, Costa SFG, Lopes MEL, Oliveira RC, Abrão FMS. O cuidar de enfermagem na terminalidade: observância dos princípios da bioética. Revista Gaúcha de Enfermagem [Internet]. 2014 [acesso 28 mar 2020];35(3):97-102. Disponível: https://seer.ufrgs.br/ RevistaGauchadeEnfermagem/article/view/46405/31518.

22. LimaYR, CostaEA. Regulamento sanitário internacional: emergências em saúde pública, medidas restritivas de liberdade e liberdades individuais. Vigilância Sanitária em Debate: Sociedade, Ciência \& Tecnologia [Internet]. 2015 [acesso 28 mar 2020]; 3(1):10-8. Disponível: http://www6.ensp.fiocruz. $\mathrm{br} / \mathrm{visa} / ? \mathrm{q}=$ node $/ 6595$.

23. Corgozinho MM, Oliveira AASAD. Equidade em saúde como marco ético da bioética. Saúde e Sociedade [Internet]. 2016 [acesso 17 set 2020]; 25, 431-441. Disponível em: https://www.scielosp.org/article/sausoc/2016. v25n2/431-441/.

24. Brasil. Ministério da saúde. Conselho Nacional de Saúde. Resolução $\mathrm{n}^{\circ}$ 466, de 12 de dezembro de 2012. Aprova as diretrizes e normas regulamentadoras de pesquisas envolvendo seres humanos. Diário Oficial da União [Internet]. 2012 [acesso 28 mar 2020]. Disponível: https://conselho. saude.gov.br/resolucoes/2012/Reso466.pdf. 


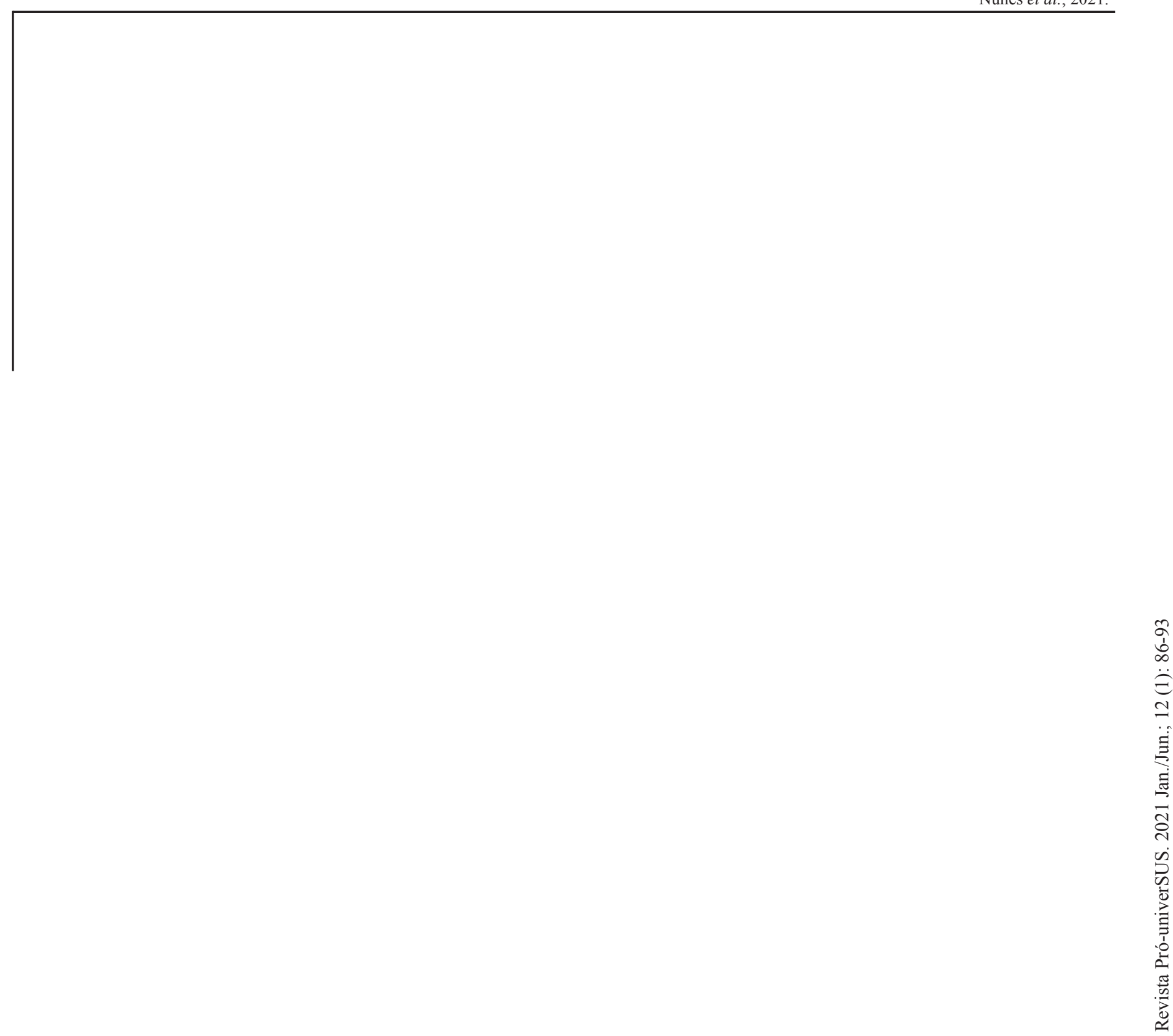

